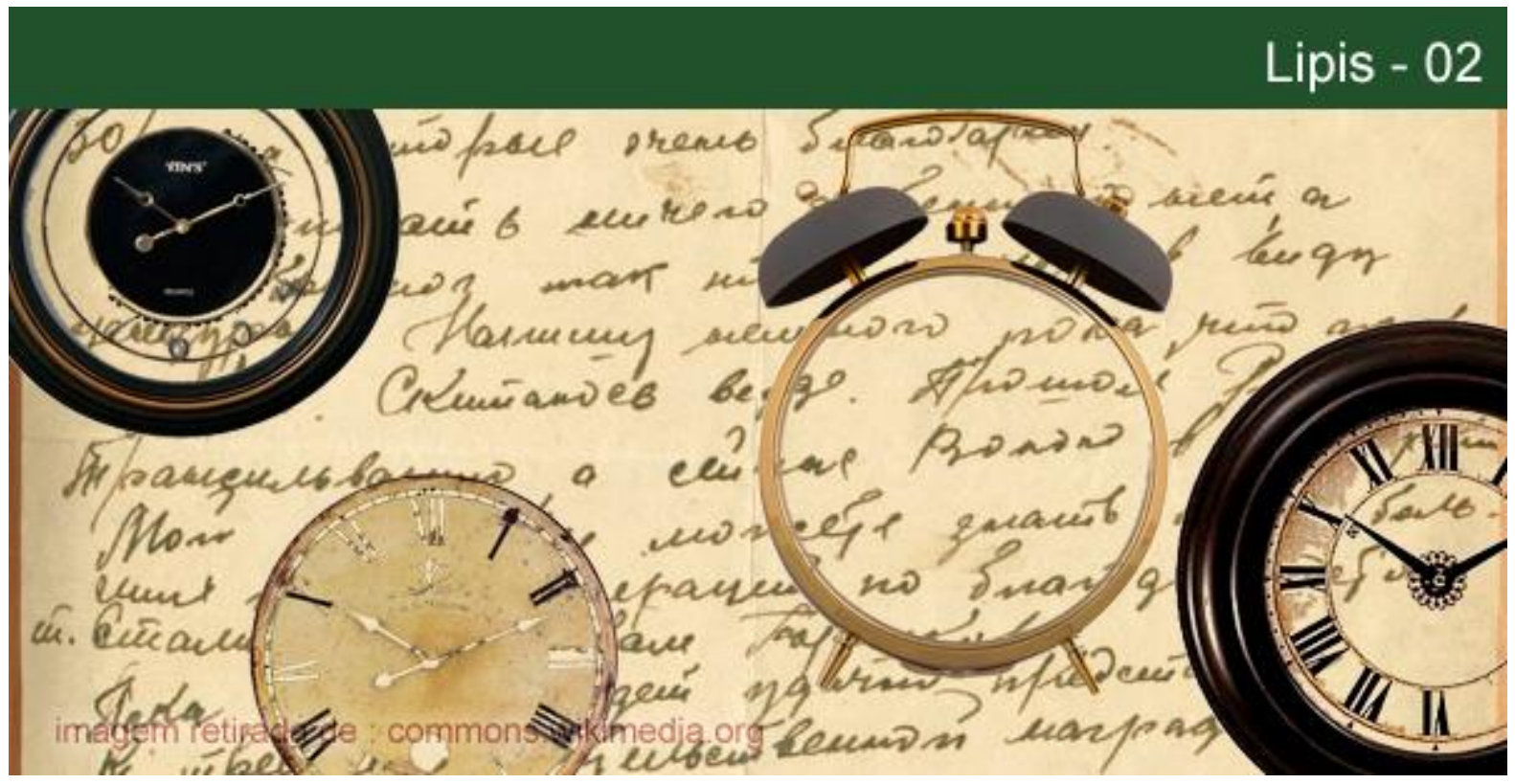

\title{
SOBRE TEMPO, PERCEPÇÃO E REPRESENTAÇÃO (ÕES)
}

\section{Maracy Domingues Alves}

Professora do Departamento de Psicologia da Pontifícia Universidade Católica (PUC-Rio) e da Universidade Católica de Petrópolis - UCP. Mestre em Psicologia Social e doutoranda em Psicologia Clinica na PUC-Rio. Estudos no Doutorado em Psicologia Social das Organizações no Instituto Superior de Ciências do Trabalho e da Empresa (ISCTE) da Universidade de Lisboa. Certificada Lean Six Sigma no grau Green Belt. Tutora do PET Saúde do Ministério da Saúde, responsável pelo projeto Análise do Trabalho Humano e Indicadores de Penosidade.Consultora em Desenvolvimento Humano e Organizacional.E-mail: maracy.alves@gmail.com.

\section{Terezinha Féres-Carneiro}

Professora Titular do Departamento de Psicologia da PUC-Rio. Doutora em Psicologia Clínica pela PUC-SP e Pós-doutora em Terapia Psicanalítica de Casal e Família pela Universidade de Paris 5 - Sorbonne. Foi presidente da Associação Nacional de Pesquisa e Pós-graduação em Psicologia (ANPEPP); membro do Comitê Assessor de Psicologia do CNPq, membro da Comissão de Avaliação da CAPES. É Cientista do Nosso Estado (1999; 2000; 2004; 2007; 2010; 2013). Foi diretora do Departamento de Psicologia da PUC-Rio (1977-1981), coordenou por vários anos o Programa de Pós-graduação em Psicologia Clínica da PUC-Rio. Desenvolve pesquisas sobre os temas: conjugalidades e parentalidades contemporâneas; famílias homoafetivas; casamento, separação e recasamento; criança, adolescente e família; e clínica de família e casal. E-mail: teferca@pucrio.br.

\section{Rita Maria Manso de Barros}

Professora Associada do Programa de Pós-graduação em Psicanálise (especialização, mestrado e doutorado), lotada no Departamento de Psicologia Clínica, e Professora Associada IV da Universidade Federal do Estado do Rio de Janeiro (UFRJ). Doutora em Teoria Psicanalítica pela UFRJ. Foi Diretora do Instituto de Psicologia da Universidade do Estado do Rio de Janeiro (UERJ) (2012-2016) e vice-diretora e coordenadora do Curso de Psicologia do Instituto de Psicologia da UERJ (2008-2012). Coordenadora do Curso de Pós-graduação a Distância em Educação Especial em Deficiência Visual (2009-2011). Membro de Projeto CAPES/COFECUB de 2012-2015, com missão na Université de Lille 3. Tem interesse, principalmente, nos seguintes temas: psicanálise, feminino, educação, violência. E-mail: ritamanso2008@gmail.com.

\section{POLÊM!CA $\mid$ LABORE (}

Polêmica - Revista Eletrônica da Uerj - Rua São Francisco Xavier, 524, $1^{\circ}$ andar bloco D, sl.1001 • Tels.: +55 21 2334-4088/4087 • http://www.e-publicacoes.uerj.br/index.php/polemica/index http://www.labore.uerj.br • laboreuerj@yahoo.com.br 
Resumo: Este artigo tem como objetivo discutir as noções de tempo, percepção e representação percorrendo alguns estudos sobre a visão clássica e articulá-la com a visão contemporânea baseada em alguns autores que se aproximam da visão winnicottiana. Reflete-se sobre o tempo no diálogo entre teologia e astrofísica, inserindo-se a concepção de universo proposta em 1932 por Freud. Foram priorizados autores que se debruçaram sobre a obra freudiana no que tange as noções de tempo, percepção e representação. Considerado pressuposto para a melhor compreensão destas três noções, apresenta-se um breve relato sobre o Projeto de 1895 de Freud. De Winnicott a tônica é o processo ativo de vivências de satisfação e frustrações como a base onde reside a ideia de criação e recriação do objeto. Na interpretação contemporânea, mostra-se a representação como um processo de dupla via no psiquismo, que navega entre a própria representação ulterior e a alucinação. Por fim, aponta-se uma aproximação da visão de representação com a visão de Moscovici em sua teoria das Representações Sociais. E com o pensamento deste autor, retoma-se a discussão epistemológica concluindo que as representações individuais ou sociais constroem a realidade e a realidade constrói as representações num processo dialético constante.

Palavras-chave: Tempo. Percepção. Representações.

\title{
ON TIME, PERCEPTION AND REPRESENTATION(S)
}

\begin{abstract}
The object of this article is to discuss the concept of time, perception and representation covering a few studies that are based on a classical point of view to then articulate it with a contemporary one, using some authors who have a very much like Winnicottian approach. It is put into consideration the concept of time in the dialogue between theology and astrophysics, introducing the conception about universe proposed by Freud in 1932. The authors who have been prioritized here studied the concept of time, perception and representation in Freud's work in depth. As precondition for a better understanding of these three concepts, a short summary of Freud's Project from 1895 is presented here. Considering Winnicott's thoughts, the keynote is the active process of satisfaction and frustration through living experiences as base to where the idea of creation and recreation of the object lies. In the contemporary interpretation about representation, the latter is shown as a two-way process in the psyche, which navigates between its own ulterior representation and also hallucination. Lastly, the article indicates the similarities between the concept of representation and Moscovici's point of view in his theory of Social Representations. Ultimately, with this author's thoughts, the epistemological discussion takes place again, with the conclusion that social or individual representations build reality, and reality builds representations, in a never-ending dialectic process.
\end{abstract}

Keywords: Time. Perception. Representations.

\section{O tempo no diálogo entre Filosofia teológica e Ciência da astrofísica}

Para Garcia-Roza (1987) “[...] a filosofia moderna constrói uma subjetividaderepresentação no interior da qual mantém as mesmas exigências e os mesmos objetivos do discurso platônico" (p. 10), e que, embora algumas modificações tenham sido feitas, o cerne do pensamento platônico permanece, na medida em que o mundo das ideias tenha sido substituído pela subjetividade e topus uranos por cogito. É preciso rebobinar esta história para compreender a citação.

Por que existe alguma coisa ao invés do nada? Tanto quanto na filosofia grega antiga, no pensamento atual essa dúvida aparece como relevante. Compartilha-se da visão de Koyré (1991) no que se refere à proposição de que os problemas da ciência atual remetem, ainda, à

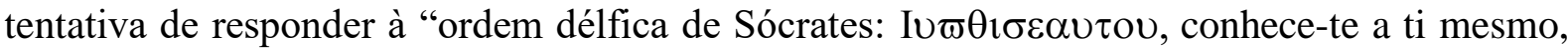
responde às perguntas: Quem sou? E onde estou? O que significa ser e o que é o mundo? E

\section{POLÊM!CA $\mid$ LABORE}

Polêmica - Revista Eletrônica da Uerj - Rua São Francisco Xavier, 524, $1^{\circ}$ andar

bloco D, sl.1001 • Tels.: +55 21 2334-4088/4087 • http://www.e-publicacoes.uerj.br/index.php/polemica/index

http://www.labore.uerj.br • laboreuerj@yahoo.com.br 
enfim, o que faço e o que devo fazer neste mundo? " (KOYRÉ, 1991, p. 26). Isto posto, cabe relembrar um dos possíveis inícios de duas das vertentes de tomada de posição epistemológica: o primado do sujeito e o primado do objeto.

É possível considerar Platão e Aristóteles como aqueles que caminharam soberbamente para que esta ordem délfica socrática se tornasse a grande discussão epistemológica. A filosofia platônica é centrada na alma. A verdade só existe no interior da alma. E os adeptos da filosofia de Platão supõem que o homem não é dotado de pensamento, "mas a alma pensa e percebe a verdade" (KOYRÉ, 1991, p. 32). Esta visão caracteriza o primado do sujeito. Na filosofia aristotélica, o desejo subjacente é o do saber científico. Desta filosofia consta o interesse pela física e pelas ciências naturais. Para Aristóteles, o mundo é um conjunto estável de naturezas que possui existência própria. $\mathrm{O}$ mundo em si não muda. Portanto, a verdade existe nele próprio. Para esta visão filosófica o mundo, então, é mais relevante do que a alma, que Platão priorizou, ressaltando, assim, o primado do objeto.

Sugere-se que tenha sido Sócrates o autor da afirmação de que existe um conceito na mente humana. Esta afirmação deu margem a que se perguntasse a origem deste conceito. Estaria o conceito desde o início na mente ou surgiu posteriormente? Platão "ensina que nada se pode aprender senão o que já se sabe e Aristóteles julga que nada se pode saber senão o que se aprendeu. E também que só se pode aprender alguma coisa se houver alguém que a tenha aprendido antes de nós, que a sabe e que nos transmite - nos impõe - esse saber" (KOYRÉ, 1991, p. 40/41).

A visão de Koyré opta pela solução tomista que supõe a individualidade espiritual e a personalidade humana como possíveis. Para ele, o espaço real se identifica com a geometria, e o movimento é considerado como uma translação de um ponto a outro na ciência moderna. $\mathrm{Na}$ física aristotélica, a percepção sensível é diferente dos conceitos matemáticos, e o movimento é entendido em dois planos: no terrestre e no celeste. No terrestre, os corpos se movem em linha reta; no celeste, em círculos. Sendo assim, os fenômenos que se manifestam na superfície da Terra seriam afetados pelo movimento desta. Uma pedra "lançada ao ar jamais cairia no lugar de onde tivesse partido, uma vez que, durante o tempo de sua queda ou de seu voo, esse lugar ter-se-ia afastado rapidamente e se encontrasse em outra parte" (KOYRÉ, 1991, p. 187). O conceito de Galileu supera o aristotélico. No entanto, Galileu mudou a própria concepção inicial. Pensou no movimento em termos de velocidade e de

\section{POLÊM!CA $\mid$ LABORE}


direção, enquanto a maior parte dos pensadores coetâneos a ele o faziam em termos de esforço (impectus) e do deslocamento. O ponto central da importância que Koyré dá à revolução galileana na história da ciência é o de que tratar o pensamento em termos de esforço e do impectus significa imaginá-lo e não pensá-lo. Para ele, imaginar é tarefa do senso comum, e à ciência cabe pensar.

No diálogo sobre Deus e a ciência empreendido pelo filósofo Guitton com os físicos Bogdanov (1993), os autores concluem que "estamos no limiar de uma revolução de pensamento, de uma ruptura epistemológica não experimentada pela filosofia desde vários séculos [...] através da via conceitual aberta pela teoria quântica, emerge uma nova representação de mundo...” (GUITTON; BOGDANOV; BOGDANOV, 1993, p. 6). E associam realidade ao pensar. Para eles "o mundo objetivo parece não existir fora da consciência que determina as suas prioridades. O Universo que nos cerca torna-se cada vez menos material; não é mais comparável a uma máquina, mas antes a um vasto pensamento" (GUITTON; BOGDANOV; BOGDANOV, 1993, p. 22). E como eles contam esta história? Escolheram o tempo de longa duração para percorrê-la. Mostram eles que a Física, antes dos anos de 1900, vincula a realidade aos estudos sobre a matéria, que é definida de um modo simples. Quando uma pedrinha se quebra, obtém-se uma poeira com moléculas formadas de átomos supostamente indivisíveis. No início dos anos de 1900, a teoria quântica aponta que, para compreender a realidade, é necessário renunciar à concepção tradicional de matéria e supor que o espaço e o tempo são ilusões. Uma partícula de matéria, segundo esta visão, pode ser detectada em dois lugares ao mesmo tempo. Portanto, a realidade fundamental não é cognoscível. Isso remete à Teoria do Conhecimento, que iniciou este texto pelo dito de Garcia-Roza. Guitton e os Bogdanov, entretanto, nos brindam com um novo saber. Os autores mostram que desta discussão da Física decorre uma ruptura na história da ciência, como já teria pressentido Foucault, ao apontar que a razão como base do sujeito determina a sua existência. O filósofo e os físicos supõem que um tipo de pensamento metalógico sobrepõe-se ao pensamento lógico. Segundo eles, tal deslocamento é importante porque,

Enquanto o campo de pensamento lógico se limita à análise sistemática dos fenômenos desconhecidos - mas, afinal, cognoscíveis -, o pensamento incognoscível; situa-se além das linguagens, além mesmo das categorias do entendimento: nada perdendo de seu rigor, toca o mistério e se esforça por descrevêlo (GUITTON; BOGDANOV; BOGDANOV, 1993, p. 9).

\section{POLÊM!CA $\mid$ LABORE}


Nesta interpretação, existem limites físicos ao conhecimento porque a realidade é cercada por fronteiras que, embora progressivamente identificadas e calculadas, são absolutamente inultrapassáveis. Assim, a Teoria do Big Bang, que se vincula à Teoria Quântica e tenta responder o porquê da existência de alguma coisa ao invés do nada - ou, em outras palavras, explicar o aparecimento do Universo -, é uma interpretação metalógica. Baseia-se em três conceituações do pensamento metalógico do físico Max Planck. Tais conceituações referem-se à constante de Planck, ao comprimento de Planck e ao tempo de Planck.

A constante de Planck marca o limite da indivisibilidade da radiação e, consequentemente, o limite extremo de toda divisibilidade. O comprimento de Planck representa o menor intervalo possível entre dois objetos aparentemente separados. E por fim, o que para esta discussão é o ponto principal, o tempo de Planck designa a menor unidade de tempo possível, representada numericamente por $10^{-43}$. Um espaço de tempo inimaginavelmente pequeno, pois o algarismo 1 é precedido de 43 zeros. É preciso ressaltar que esta visão na Física se contrapõe aos físicos clássicos - entre eles Einstein - que supunham que a realidade fosse cognoscível. Na Física, baseada na Teoria Quântica, a realidade é velada, portanto não é cognoscível. Segundo Guitton e os Bogdanov, "aceitar esta conclusão é descobrir que existe uma solução alternativa para a estranheza física: a estranheza lógica" (GUITTON; BOGDANOV; BOGDANOV, 1993, p. 11).

Mas afinal, do que trata a Teoria do Big Bang? É possível dizer que se trata de contar a história dos últimos 15 bilhões de anos. Seria como retroceder ao tempo zero e explicar a origem de tudo o que existe hoje. E é disso que trata o diálogo entre o filósofo e os irmãos Bogdanov. Eles contam essa história com perguntas e tentativas de respostas, em um diálogo, quase duelo, que intriga e esclarece tal como uma conversa maiêutica.

Muitos objetos são usados no cotidiano por várias pessoas sem que disso resulte uma curiosidade sobre qual força os tenha dotado das formas que apresentam hoje. Faz-se uso do objeto no momento que se precisa dele. Tais objetos, por mais familiares que sejam ao seu usuário, podem, por outro lado, conduzir a grandes enigmas. Uma chave de ferro, como o exemplo citado pelos autores, é um objeto muito usado diariamente por um grande número de pessoas. Ninguém precisa retroceder no tempo e refazer a história dos átomos que a compõem para abrir uma tranca ou acionar uma ignição com esta chave de ferro. Entretanto a ciência

\section{POLÊM!CA $\mid$ LABORE}


precisa, pois é na busca da compreensão dos fenômenos do Universo que sacia a sua curiosidade.

Assim, o que seria encontrado na história invisível desta chave? É possível retroceder alguns anos e verificar que esta chave estaria no âmago de uma rocha na forma de minério bruto. E com esta resposta estaria encerrada a dúvida sobre a história da chave de ferro. $\mathrm{O}$ bloco de ferro que deu origem à chave existia dentro da rocha havia bilhões de anos. E esse novo dado mostra que o metal da chave pode ser mais antigo do que a própria Terra, cuja idade é estimada em 4,5 bilhões de anos. E, como o ferro é considerado o elemento mais estável do Universo, afirma a Física que, antes da existência da Terra ou mesmo do Sol - há cerca de oito ou dez bilhões de anos -, o metal da chave já flutuava no espaço interestelar, sob a forma de uma nuvem. E esta nuvem continha quantidades de elementos pesados necessários à formação do próprio Sistema Solar. Admitindo-se que esta chave, outrora, existia sob a forma de átomos de ferro perdidos em uma nuvem de matéria nascente, cabe-se perguntar de onde surgiu esta nuvem? Os físicos, sem dúvida, responderiam, facilmente, que a nuvem surgiu de uma estrela, de um sol que já existia antes do sol da Via Láctea e que explodiu, há dez ou 12 bilhões de anos.

\footnotetext{
Nessa época, o Universo era essencialmente constituído de imensas nuvens de hidrogênio que se condensaram, se reaqueceram e acabaram por acender-se, formando as primeiras estrelas gigantes. (...). No fim de uma vida relativamente breve - apenas algumas dezenas de milhões de anos -, essas estrelas gigantes explodem, projetando no espaço interestelar os materiais que servirão para fabricar outras estrelas menores, chamadas estrelas de segunda geração, assim como seus planetas e os metais que eles contêm (GUITTON; BOGDANOV; BOGDANOV, 1993, p. 22).
}

Tudo que se encontra na terra atualmente, inclusive a chave de ferro, segundo esta concepção da ciência, seria apenas o resíduo gerado pela explosão dessa antiga estrela. Entretanto, a explosão dessa estrela pode ser entendida como o Bang dessa história, mas ainda não tão Big. Para chegar ao Big Bang, é preciso retroceder ainda mais um pouco no tempo. Ou será preciso retroceder mais um muito? Afinal o que aconteceu há 15 bilhões de anos ou há $10^{-43}$ no tempo de Planck?

Os Bogdanov explicam que haveria no tempo zero uma singularidade microcósmica no vácuo, impensavelmente pequena, que reuniria planetas, sóis e galáxias aos bilhões. A Física moderna aponta, então, que o Universo surgiu a partir de uma explosão - o Big Bang -, que provocou a expansão da matéria. As galáxias afastam-se uma das outras sob o impulso

\section{POLÊM!CA $\mid$ LABORE}


desta explosão. Tal fenômeno de expansão, segundo esta teoria, continua até hoje. Desta forma, bastaria medir a velocidade de afastamento dessas galáxias para poder retroceder ao tempo zero da singularidade microcósmica “...como se víssemos um filme ao contrário. Rebobinando o grande filme cósmico imagem por imagem, acabaremos por descobrir o momento preciso em que o Universo inteiro tinha o tamanho de uma cabeça de alfinete" (GUITTON; BOGDANOV; BOGDANOV, 1993, p. 23).

Os astrofísicos tomam como origem de todo o Universo e do que ele contém inclusive a chave de ferro - os primeiros bilionésimos de segundo que se seguiram à criação. Os eventos, segundo este paradigma, sucediam-se em um ritmo de tal imensidão que durante esses bilionésimos de segundo aconteceram mais coisas do que nos bilhões de anos que se seguiram. Então, após o instante original, entre $10^{-35}$ segundo e $10^{-32}$ segundo, surgiu a era inflacionária. Esta fase recebe este nome porque o Universo, que teria o tamanho de um núcleo atômico, infla por um fator de $10^{50}$. A grandeza da expansão do Universo, nesta era inflacionária, pode ser comparada ao tamanho de uma maça de dez centímetros de diâmetro. Este foi o momento culminante da expansão do Universo desde a grande explosão inicial. Desde a era inflacionária até hoje o Universo aumentou por um fator de $10^{9}$. No instante $10^{-32}$ segundo, existia apenas uma partícula, denominada "partícula X”, que veicularia um campo de forças sem, entretanto, a matéria. Foi no momento $10^{-31}$ segundo que as partículas $\mathrm{X}$ dão origem às primeiras partículas de matéria que, por sua vez, dão origem a flutuações de densidade, através das quais surgem irregularidades de todos os tipos. O Universo mede, então, treze metros de diâmetro, e sua temperatura é extremamente alta. Ao mesmo tempo em que ocorre a expansão do Universo, ocorre também o seu resfriamento. E essa história invisível percorrida até então, durou o equivalente a cerca de três minutos no tempo de Planck. Durante milhões de anos o Universo permanece em radiações e em um gás turbulento. As primeiras estrelas se formam em meio a estes imensos turbilhões de gás. No núcleo das estrelas os átomos de hidrogênio e de hélio se fundem para dar origem aos elementos pesados, como o ferro daquela chave. Esta seria a história invisível da chave de ferro. Os Bogdanov, astrofísicos adeptos da teoria quântica, encerram a possibilidade de respostas à retomada da pergunta inicial do teólogo Guitton: Por que existe alguma coisa ao invés do nada? E Guitton permaneceu sem resposta por parte da ciência astrofísica, o que permitiu, na sequência,

\section{POLÊM!CA $\mid$ LABORE}


afirmar seu ponto de vista teológico de que quanto mais a Ciência avança, mais se aproxima de Deus.

Em 1932, na nova série de conferências, embora não proferidas, Freud (1932, sd) pondera que

nenhum leitor de um trabalho sobre Astronomia se sentirá fraudado e superior à Ciência se lhe mostram os limites entre os quais nosso conhecimento do Universo se desvanece no nebuloso. Só em Psicologia sucede coisa diferente; neste setor se manifesta plenamente a incapacidade constitucional do homem para a investigação científica (FREUD, 1932, sd, p. 8).

A psicanálise conduz a qual concepção do Universo? Ao responder a esta interrogação, Freud aponta que a Weltanschauung (concepção do Universo) "é uma construção intelectual que resolve unitariamente, baseada em uma hipótese superior, todos os problemas de nosso ser e na qual, portanto, nada fica por responder, e tudo o que desperta nosso interesse encontra o lugar determinado" (FREUD, 1932, sd, p. 167). E após discutir criticamente as concepções do ponto de vista da religiosidade e da visão político-econômica do marxismo, afirma que a psicanálise é

Incapaz de criar uma concepção do Universo a ela peculiar. Não o necessita; é uma parcela da ciência, e pode agregar-se à concepção científica do Universo. Porém, esta mal merece nome pomposo, pois não concebe tudo, está bastante imperfeita e não aspira a concretização nem a formação de sistemas. (...). Uma concepção do Universo baseada na Ciência tem, fora da acentuação do mundo exterior real, traços essencialmente negativos, como a limitação à verdade e a repulsa das ilusões (FREUD, 1932, sd, p. 192).

\section{O tempo em Freud}

E a concepção de Freud sobre o tempo? É tal como esta visão teológica e astrofísica? De que forma o incognoscível e a acronia se apresentam no pensamento freudiano? Como a concepção psicanalítica imbrica passado-presente-futuro? Em Os tempos de Freud, Gondar (1995) propicia um passeio por estas questões. A recusa do tempo, segundo a autora, é o viés predominante no campo filosófico na medida em que

[...] a questão filosófica primordial consiste em extrair, daquilo que muda e passa, o que permanece estável e imutável. [...] Em Platão o tempo é uma imagem móvel da eternidade; é uma cópia imperfeita de uma ideia perfeita. [...] É certo que em Aristóteles não existe mais um mundo supra terreno de ideias puras; as essências não pairam sobre a nossa realidade, mas dela devem ser extraídas. Porém, é ainda a mesma motivação de recusa do tempo que permanece. O tempo deixa de estar

\section{POLÊM!CA $\mid$ LABORE}

Polêmica - Revista Eletrônica da Uerj - Rua São Francisco Xavier, 524, $1^{\circ}$ andar

bloco D, sl.1001 • Tels.: +55 21 2334-4088/4087 • http://www.e-publicacoes.uerj.br/index.php/polemica/index

http://www.labore.uerj.br • laboreuerj@yahoo.com.br 
submetido a uma ideia perfeita para tornar-se subordinado ao movimento (GONDAR, 1995, p. 3).

$\mathrm{O}$ argumento principal apontado é o de que somente quando a recusa do tempo se ameniza nas discussões filosóficas, é que passa a emergir o sujeito neste campo, condição necessária para que a temporalidade também seja problematizada. E neste sentido, a visão de Descartes, seguida por Kant, Husserl e Heidegger, abre a possibilidade de discussões sobre outro prisma em relação ao tempo. Nelas inclui-se o rastreamento do tema nos escritos de Freud, segundo a autora. Neste rastreamento, três temas são relevantes: finitude, tópica temporal e tempo no cogito.

Diferente da visão clássica de racionalidade, a de Freud não considera o tempo como ilusão, mas sim a eternidade, na medida em que afirma a finitude. Neste sentido, considerando-se a contribuição epistemológica de Freud, é possível dizer que esta rechaça a ideia de conhecimento completo, porque, para ele, na verdade o que reside é o desejo que impele o sujeito a perceber o mundo. Na interpretação de Gondar (1995), essa percepção do mundo pelo desejo - velado à consciência - se articula com o pensamento. Sendo inconsciente, o desejo não é previsível e nem cognoscível e, assim, desfaz-se a possibilidade de infinito e absoluto.

Se nenhum saber pode ter a pretensão a um conhecimento completo, não é apenas porque o real não pode ser esgotado no simbólico, mas porque o homem desconhece o próprio desejo que o move; nesse desejo residiria a verdade, como um próprio do homem que é, em si mesmo, incognoscível (GONDAR, 1995, p. 9).

No que se refere à tópica temporal, cabe lembrar que, por tópica, Freud denomina a diferenciação das localizações psíquicas em esquemas. Tópica, ou tópico, no vocabulário da Psicanálise de Laplanche e Pontalis (LAPLANCHE, 2001) é definida como,

Teoria ou ponto de vista que supõe uma diferenciação do aparelho psíquico em certo número de sistemas dotados de características ou funções diferentes e dispostos em uma certa ordem uns em relação aos outros, o que permite considerá-los metaforicamente como lugares psíquicos de que podemos fornecer uma representação figurada espacialmente (LAPLANCHE, 2001, p. 505).

Sendo assim, não seria uma discussão sobre o espaço e não sobre o tempo? Três aspectos respondem esta dúvida. O primeiro se refere à suposição de que, se o aparelho psíquico é um sistema que funciona em uma certa ordem, cabe trazer a categoria tempo para a teorização sobre as tópicas freudianas.

\section{POLÊM!CA $\mid$ LABORE}


O segundo aspecto, conforme mostra Gondar (1995), decorre da visão de que, ao valorizar a diferenciação qualitativa e específica em funcionamento, Freud está dando outro sabor à tópica que não o espacial. Neste caso, o valor exaltado é função e relação.

Um apontamento importante de Laplanche e Pontalis (LAPLANCHE, 2001) sobre esta argumentação traz a concepção de inconsciente para esta discussão.

[...] o próprio inconsciente, compreende uma organização por camadas, a investigação analítica faz-se necessariamente por determinadas vias que supõem uma determinada ordem entre os grupos de representações. A organização das lembranças, arrumadas em verdadeiros 'arquivos' ao redor de um núcleo patogênico, não é apenas cronológica; tem também um sentido lógico, pois as associações entre as diversas representações realizam-se segundo modalidades diversas (LAPLANCHE, 2001, p. 506).

O terceiro aspecto, tomado emprestado do psicanalista francês Jacques Lacan por Gondar (1995), se refere à ideia de processos psíquicos, que é compreendida como conjunta à interpretação estrutural, condição necessária para a compreensão do movimento e rearranjo do inconsciente. Neste caso, mais um argumento para incluir a visão temporal da tópica.

Sobre o tempo no cogito, sintetizando Descartes e Kant, Gondar (1995) mostra a subversão freudiana ao cogito. Sobre a posição cartesiana das quatro fontes de conhecimento - memória, sentidos, conhecimento objetivo do mundo e conhecimento das essências -, é argumentado que sempre se interpõe uma dúvida que refuta a confiabilidade. Sobre a memória, esta oposição menciona a impossibilidade de garantir a continuidade de ideias. Aos sentidos, sugere-se que as impressões sensíveis estão sujeitas à transitoriedade. Ao conhecimento objetivo do mundo indica-se a alternância entre sono e vigília. E quanto à essência, o surgimento inusitado de um gênio maligno que falseasse a realidade. Só excluindo a categoria tempo seria possível tratar estas fontes com a confiabilidade necessária, tentativa realizada por Descartes, mas sem lograr êxito, escreve Gondar. "O fato é que Descartes se desvia do tempo a cada passo de suas Meditações" (GONDAR, 1995, p. 18). E aponta os escritos kantianos como reforçadores dessa ideia. Se em Descartes há uma relação direta entre determinante e determinado, Eu penso - Sou uma coisa que pensa, em Kant não há possibilidade que se configure esta relação porque "a forma pela qual a existência indeterminada é determinável só pode ser a forma do tempo" (KANT apud GONDAR, 1995, p. 19).

\section{POLÊM!CA $\mid$ LABORE}


A subversão freudiana ao cogito ocorre, nesta história do tempo em Freud, entre a primeira e a segunda tópica. E, novamente insere-se a visão cartesiana para a argumentação em oposição. Em Freud o sujeito se identifica com a consciência pela, também, identificação com o cogito. Considerando-se o inconsciente, o sujeito não pode ser em um tempo contínuo, mas a posteriori, na medida em que Freud aponta para a consequência do trabalho das pulsões e também para a constatação de que os impulsos chegam, eventualmente, como se fossem de estranhos. A compulsão à repetição, decorrente da sequência dos estudos de Freud, é justamente o conceito que permite reinserir ao cogito a temporalidade retirada em Descartes. E considerando que o pensamento freudiano nesta questão também difere do apontado por Kant, Gondar (1995) mostra que "o sujeito kantiano não é inconsciente e o inconsciente freudiano não é transcendental" (GONDAR, 1995, p. 22).

Com base nesta descrição do tempo em Freud, é possível pensar em uma teoria freudiana do tempo? Para Gondar (1995) existem duas versões de teorização de Freud em relação ao tempo. Uma negativa - e é a mais conhecida -, que aponta os processos atemporais. E a outra a positiva, menos discutida, mas que se relaciona à modalidade temporal da consciência.

Sobre a atemporalidade do inconsciente, são relevadas três asserções que aparentemente se traduzem pelo mesmo significado. "Os processos mentais inconscientes não são ordenados temporalmente; o tempo de modo algum os altera; e a ideia de tempo não lhes pode ser aplicada" (GONDAR, 195, p. 30). Na análise da autora, e considerando os diferentes significados das asserções, a primeira e a terceira são rechaçadas na medida em que à ideia de processo está implicada, necessariamente, a existência temporal. Em relação a asserção de que o tempo de modo algum os altera, a argumentação é parcimoniosa porque a autora questiona:

É possível se pensar em processos que não se desgastam (...) mesmo assim, se esses processos consistem na articulação de representações inconscientes, que podem ser a qualquer momento rearranjadas, é difícil conceber que alguma modalidade temporal não esteja implicada nesses rearranjos (GONDAR, 1995, p. 30).

Sobre a versão positiva referida a consciência e tempo, dois aspectos são apontados. O primeiro relaciona-se ao tempo vivido, e o segundo, à destituição da consciência. O tempo vivido é caracterizado como algo intrínseco à subjetividade e, sendo assim, é uma experiência não compartilhável e relacionada à consciência. Ao tratar da destituição da consciência, a autora mostra as duas camadas da consciência do sistema Pcpt-Cs. A primeira funciona como

\section{POLÊM!CA $\mid$ LABORE}


um escudo protetor do excesso de estímulo, e a segunda camada, como a superfície que recebe os estímulos já abrandados. Entretanto, o sistema Pcpt-Cs, ao receber as estimulações, não retém qualquer traço, dependendo dos sistemas mnemônicos pré-conscientes e inconscientes que teriam esta função com a participação protagonista do Ego na classificação das excitações. E somente durante a classificação a consciência emerge, para, posteriormente, extinguir-se. Ao tratar a consciência como instantes a serviço de outras instâncias do psiquismo, Freud abandona a consciência para firmar o inconsciente como objeto de estudo.

No escopo de sua análise do tema, Gondar (1995) pondera que há uma mistura na concepção de tempo nos escritos de Freud. O tema aparece em cinco discussões. A primeira refere-se à concepção de representação no funcionamento do sistema percepção-consciência. A segunda é tratada na lógica temporal do modo inconsciente de operação. O tempo da pulsão é a terceira. A quarta compreende três outras acepções: a do tempo mítico, tempo das origens do psiquismo e da constituição do sujeito. E, por último, a existência da herança arcaica no psiquismo. Ao descrever mais amiúde cada uma destas cinco discussões, a autora conclui: "Pensar o tempo sob a égide da disjunção e da diferença; fornecer um estatuto teórico ao puro devir, como fonte de modalidades temporais diversas; postular um determinismo a posteriori, com uma plasticidade sem precedentes na esfera científica” (GONDAR, 1995, p. 133).

\section{Uma pitada do Projeto de 1895}

Mas afinal, o que é o aparelho psíquico em Freud? O que são os sistemas $\varphi, \psi$ e $\omega$ ? E do que tratam, efetivamente, os sistemas Ics, Pcs e Cs? Como estão inseridos memória, percepção e representação nestes sistemas?

Ao contar a história do Projeto de Freud, escrito em 1895, mas efetivamente publicado em 1950, Garcia-Roza (1991) ressalta que a concepção deste trabalho visou apresentar a psicologia como ciência natural. Este fato parece "remar contra a maré" expressada à época pela Fenomenologia do Espírito de Hegel e pela Psicologia Comparada de Dilthey. Por quê? A visão da época associava as ciências da natureza às categorias de significação e força. Entretanto, Garcia-Roza pontua várias ideias convergentes entre Herbart e Exner, ambas de concepções quantitativas, com as apresentadas por Freud, no Projeto e em outros escritos. Vale ressaltar que esta visão freudiana da psicologia como ciência natural traduz-se por sua inserção no cenário positivista da época, mas com interseção, embora não claramente

\section{POLÊM!CA $\mid$ LABORE}


denominada, com a filosofia do espírito. Mas o foco principal de Freud nesta postulação diz respeito à exigência de rigor teórico-conceitual, do qual ele nunca descuidou.

Duas são as ideias que norteiam o Projeto. A primeira pretendia conceber uma lei geral do movimento para diferenciar atividade e repouso. A segunda preceitua que os neurônios são partículas materiais. E, embora estas ideias não fossem originais, pois foram estudadas anteriormente, no trabalho de Freud adquirem uma nova configuração porque são articuladas entre si, estabelecendo uma diferença estrutural. Assim sendo, no Projeto os neurônios $\varphi, \psi$ e $\omega$ são descritos com visão sistêmica. A proposta de Freud utiliza, portanto, um modelo sistêmico de natureza hipotética que se caracteriza como uma teoria neuronal sem pretensão de apresentar uma descrição anatômica do neurônio, que era o interesse da histologia da época. Ao contrário, Freud pretende apresentar uma metapsicologia. "Os neurônios são condutores de energia, sendo que dependendo do sistema por eles formado, são capazes de armazenar energia" (GARCIA-ROZA, 1991, p. 80).

Com base nos casos de histeria e de neurose obsessiva, Freud "levanta a hipótese de uma proporcionalidade entre a intensidade dos traumas e a intensidade dos sistemas por eles produzidos" (GARCIA-ROZA, 1991, p. 83). E, a partir disto, propõe a distinção entre quantidades e intensidades e, em seguida, o princípio da constância que se relaciona à regulação da intensidade.

Um aspecto interessante desta temática relacionada ao princípio da constância se refere à noção de investimento, que designa uma representação cujo afeto não foi descarregado. Nesta discussão surge uma relação entre o princípio da inércia e o princípio do prazer. E, apontando o evitar do desprazer, Garcia-Roza mostra que

o desprazer é identificado com o aumento do estímulo, enquanto que o prazer resulta de sua diminuição. Como o princípio da inércia neurônica enuncia a tendência do neurônio a aliviar-se da quantidade, somos tentados a identificar o princípio de inércia com o princípio de prazer (GARCIA-ROZA, 1991, p. 90).

Entretanto, o próprio Freud percebe a necessidade de substituir o princípio da inércia pelo da constância para a regulação dos processos psíquicos. E é deste estudo que surge a distinção entre processos primários e processos secundários, que posteriormente, por sua relação temporal, terão papel fundamental na definição de ego (Eu) como resultado da diferenciação progressiva do id (Isso). Esses processos, entendidos como modos de funcionamento do aparelho psíquico, podem ser entendidos de duas formas, segundo

\section{POLÊM!CA $\mid$ LABORE}


Laplanche e Pontalis (LAPLANCHE, 2001). De um lado, descrito pela visão tópica, o primário refere-se ao sistema inconsciente, e o secundário pelo sistema pré-conscienteconsciente. Na segunda forma, tratado pela visão econômico-dinâmica, no processo primário ocorre o livre escoamento da energia psíquica, e no secundário a energia escoa de forma controlada. Em ambos os processos, a representação tem funções diferentes. No primário, após o escoamento a representação é transferida de um ponto a outro pelos mecanismos de deslocamento e de condensação. No secundário, “a energia começa por estar 'ligada' antes de se escoar de forma controlada: as representações são investidas de uma maneira mais estável, a satisfação é adiada, permitindo assim experiências mentais que põem à prova os diferentes caminhos possíveis de satisfação" (LAPLANCHE, 2001, p. 371).

Com a leitura da interpretação de sonhos (FREUD, 1900, sd) é possível compreender o fluxo destes processos. As representações ocorrem em diferentes intensidades e se tornam suscetíveis de derivação para outras representações que, em continuidade, geram um conjunto de representações providas de grande intensidade. Esta dinâmica é denominada condensação e é o processo pelo qual são obtidas as intensidades necessárias para o caminho que leva ao sistema de percepção. Entretanto, através da livre transferência das intensidades são constituídas representações intermediárias para além daquelas que transferem suas energias reciprocamente e, este fenômeno pode levar "a alguma coisa inaudita no curso normal das representações, no qual se trata, sobretudo da escolha e conservação do verdadeiro elemento de representação" (FREUD, 1900, sd, p. 365).

Na sequência dos estudos sobre o Projeto associadas ao conceito de investimento estão duas hipóteses freudianas importantes no que tange ao entendimento da memória. A primeira refere-se às barreiras de contato (sinapses), e a segunda, à facilitação.

A importância para o entendimento da memória propiciada pela hipótese das barreiras de contato está no fato de que, na memória neurônica, é possível distinguir os neurônios permeáveis (neurônios $\varphi$ ) $\square$ dos impermeáveis (neurônios $\psi$ ). Este relacionado à memória e aquele à percepção, na medida em que a fluidez necessária no processo perceptivo requer permeabilidade. E esse aspecto está relacionado com a ideia de Freud sobre as duas características do sistema nervoso: a recepção de estímulos externos (sistema $\varphi$ ) e a descarga de excitações endógenas (

\section{POLÊM!CA $\mid$ LABORE}


pela mediação dos órgãos dos sentidos, mas o mesmo não ocorre com o sistema $\psi$ em relação aos estímulos endógenos. Nesta dinâmica, ocorre a mola pulsional do mecanismo psíquico.

A segunda hipótese, a facilitação, configura-se como crucial para a visão de Freud do aparato psíquico. Conforme mostra Garcia-Roza (1991), “a distinção entre neurônios permeáveis e neurônios impermeáveis é o suporte necessário para Freud conceber o sistema como um aparato de memória que se forma por estratificação sucessiva" (p. 98). Este processo da memória é constituído por facilitações na construção do trilhamento necessário para o reordenamento de novos nexos. $\varphi, \psi$ e $\omega$.

Enquanto os sistemas $\varphi$ e $\psi$ são quantitativos e estão relacionados ao inconsciente, o sistema $\omega \square$ é qualitativo e está relacionado à consciência. A qualidade está relacionada aos aspectos sensíveis da percepção, tais como som, cor, textura; e se origina, na visão de Freud, no sistema $\omega$ "que é excitado junto com a percepção, mas não com a reprodução, e cujos estados de excitação produzem as diversas qualidades - ou seja, são sensações conscientes" (FREUD apud GARCIA-ROZA, 1991, p. 103). Sendo assim, é este sistema $\omega$ o responsável pela percepção-consciência. Os três sistemas atuam interativamente: $\omega$ é alimentado por $\varphi$, que fornece informações para $\psi$.

Surge uma situação, nesta primeira tópica, em que a solução de Freud reforça o rastreamento de Gondar sobre o tempo. Os neurônios $\omega$ são, na afirmação de Freud, órgãos de percepção que, entretanto, têm a permeabilidade implicada na fluidez necessária. Se, no caso dos neurônios $\varphi$, a permeabilidade é completa por estar em contato direto com a fonte endógena, a quantidade de energia é maior; e, no caso dos neurônios $\psi$, estes terem energia menor por sua capacidade de criar barreiras de contato; cria-se uma dúvida. Se a carga de energia recebida pelos neurônios $\omega$ é menor por ser intermediado, por que não têm a capacidade maior de criar barreiras de contato? É justamente na resposta a esta dúvida que surge a temporalidade.

Os neurônios não são capazes de receber $Q$, o que eles recebem é uma temporalidade ou um período de excitação que lhes possibilita uma carga mínima de Q necessária para a consciência. (...) ele (Freud) faz uma correção do esquema anterior e afirma que existem três formas segundo as quais os neurônios podem se afetar mutuamente: $1^{\circ}$ ) transferindo quantidade (Q) entre si; $2^{\circ}$ ) transferindo qualidade entre si e $3^{\circ}$ ) exercendo uma forma de excitação recíproca (GARCIAROZA, 1987, p. 53).

\section{POLÊM!CA $\mid$ LABORE}


Decorre deste modelo de funcionamento a noção freudiana de experiência de satisfação e, na sequência, a emergência do ego que configura a reestruturação, pela segunda tópica, da visão freudiana de aparelho psíquico. A noção de experiência de satisfação está ligada ao estado de desamparo original do ser humano, um dos principais temas retomado, de Freud, na visão winnicottiana. E, conforme mostram Laplanche e Pontalis (LAPLANCHE, 2001) "a vivência de satisfação - real e alucinatória - é a noção fundamental da problemática freudiana de satisfação; nela se vêm articular o apaziguamento da necessidade e a realização do desejo" (LAPLANCHE, 2001, p. 531).

A segunda tópica, embora não represente uma ruptura no conjunto da teoria psicanalítica, aponta o interesse para outras direções que não as da percepção e consciência. Os conceitos de ego, id e superego (Eu, Isso e Supereu). Assim, o ego, nesta versão, tem sua origem no sistema Pcpt-Cs e do seu núcleo segue pelo Pc e pelo Ics. Sendo o id a porção inacessível do aparelho psíquico, a função do ego, como instância duplamente modificada do id e do superego, "é servir de mediador entre o id e o mundo externo, o que coloca em confrontação os dois princípios reguladores do aparelho psíquico: o princípio de prazer e o princípio da realidade" (GARCIA-ROZA, 1987, p. 207).

\section{Algumas pontuações contemporâneas}

$\mathrm{Na}$ argumentação sobre a importância das relações objetais na capacidade ulterior de se comunicar, Winnicott defende que o objeto de subjetivo se torna percebido objetivamente em função da experiência de onipotência notada no período de lactância. Essa conceituação sustenta a ideia de que a maturação psicológica está diretamente relacionada à qualidade do ambiente favorável. Essa ideia denota o discurso psicanalítico pedagógico herdado de Anna Freud, mas contraposto pela visão kleiniana, nos postulados de Winnicott. E esse ponto é trazido por Zornig (2008) como aquele no qual reside a importância da distinção entre infância concretamente vivida e infantil nos estudos freudianos. O conceito de infantil referese tanto à constituição da neurose infantil quanto ao "percurso edípico, tendo como função retroativa que pode ser reativada pela transferência" (p. 49). E sendo assim, não se trata de um local onde as lembranças ficam armazenadas em sua forma original, mas, como aponta Tanis (1995), “é o modo pelo qual o psíquico registra ao mesmo tempo em que se constitui pelas Erlebnisse (experiências) infantis" (p. 33).

\section{POLÊM!CA $\mid$ LABORE}


Por mais paradoxal que possa parecer, a visão de Winnicott (1983) aponta que "a mudança do objeto de subjetivo para percebido objetivamente é realizada menos efetivamente por satisfações do que por frustrações" (p. 165). Neste processo ativo de vivências de satisfação e frustrações é que reside a ideia de criação e recriação do objeto. Essa ideia se configura como uma das essenciais à concepção psicanalítica apresentada por Ogden (2010). Com inspiração em Wilfred Bion, psicanalista britânico, Ogden relata a importância de sonhar durante o sono e na vigília inconsciente. Para ele, "se uma pessoa é incapaz de transformar impressões sensoriais brutas em elementos inconscientes da experiência que possam ser ligados, ela é incapaz de gerar pensamentos-sonho inconscientes e, consequentemente, não pode sonhar" (OGDEN, 2010, p. 19). Neste contexto, o autor também releva o conceito de holding como postulado na visão de Winnicott. "Inicialmente, a mãe protege a continuidade do ser do bebê, em parte isolando-o do aspecto não-eu do tempo. A maturação envolve a gradual internalização, pelo bebê, do holding materno da continuidade de ser do bebê ao longo do tempo e de seu fluxo emocional" (OGDEN, 2010, p. 121).

E qual a pontuação contemporânea sobre a percepção e a representação? Segundo Botella e Botella (2002), os estudos sobre percepção não empreenderam um conceito preciso na psicanálise. Para os autores, "nos textos freudianos, ela aparece muitas vezes reduzida a uma função elementar, utilizada antes mais especificamente em acepções tais como auto percepção, percepção interna ou endopsíquica, ou integrada em uma concepção teórica que considera o id como seu próprio sistema de percepção" (p. 178). Entretanto, da mesma forma que sinalizam esta falha, reconhecem a importância "que Freud dá ao retorno, durante o tratamento, da realidade do passado, da verdade histórica, sob forma de lembrança representada” (p. 179). Mas é na análise da segunda tópica que os autores outorgam a Freud o bem-posto em relação ao perceptivo. Essa coroação se dá pela constatação da prioridade em relacionar percepção e representação no estudo do psiquismo. "A segunda tópica é o produto da necessidade de poder pensar o psiquismo também enquanto conjunto dos fenômenos submetidos a mudanças; em suma, em termos de processo e não unicamente de conteúdos representacionais e de sistemas" (BOTELLA; BOTELLA, 2002, p. 184). A importância desta análise dos Botella reside no fato de descrever a representação como um processo de dupla via no psiquismo, que navega entre a própria representação ulterior e a alucinação, o que permite novas possibilidades no manejo da clínica psicanalítica.

\section{POLÊM!CA $\mid$ LABORE}




\title{
Sobre as possíveis articulações com as representações sociais
}

Sobre as discussões propostas referidas à construção da realidade a partir do senso comum ou delimitada como área da ciência, Moscovici (1978) realizou um grande percurso acadêmico no âmbito das ciências sociais, com sua Teoria das Representações Sociais. Suas discussões iniciam-se, na verdade, com inspiração na sociologia molecular (MOSCOVICI, 1990). Esta sociologia molecular é pautada no conceito de redes e representações que aponta o princípio da complementaridade de Bohr ${ }^{1}$. Neste princípio a descrição dos fenômenos físicos e a descrição dos objetos atômicos invisíveis não se excluem, eles se complementam. Com base neste estudo é possível refletir sobre a lógica simbólica. O autor supõe que o verdadeiro elemento atômico da sociedade é a ação mental recíproca de onde tudo provém e para onde tudo retorna. E divide os fatos em duas classes: os fatos anônimos e os fatos nominados. Refere-se ao primeiro como os minúsculos acontecimentos e os pequenos fatos que vão sendo colecionados através da observação dos estados físicos e dos estados da alma. Quanto aos fatos nominados, aponta que só existem através de categorias que os classificam e revestem-nos de uniformidade. Assim como os átomos em física, os indivíduos só têm realidade através das interações. Para ele, os costumes, as leis, as nações são manifestações na vida em comum, assim como a matéria com relação às forças atômicas que a cimentam.

Moscovici (2003) articula as ideias de pensamento primitivo, ciência e senso comum. Para ele,

\begin{abstract}
a crença em que o pensamento primitivo "está baseado é uma crença no poder ilimitado da mente em conformar a realidade, em penetrá-la e ativá-la e em determinar o curso dos acontecimentos. A crença em que o pensamento científico moderno está baseado é exatamente o oposto, isto é, um pensamento no poder ilimitado dos objetos de conformar o pensamento, de determinar completamente sua evolução e de ser interiorizado na e pela mente. No primeiro caso, o pensamento é visto como agindo sobre a realidade; no segundo, como uma reação à realidade humana; em uma, o objeto emerge como uma réplica do pensamento; na outra, o pensamento é uma réplica do objeto; e se para o primeiro, nossos desejos se tornam realidade - ou wishful thinking - então, para o segundo, pensar passa a ser transformar a realidade em nossos desejos, despersonalizá-los. (...) enquanto a mente primitiva se amedronta diante das forças da natureza, a mente científica se amedronta diante do poder do pensamento (...) ambas, a seu modo, representam um aspecto real da relação entre nossos mundos internos e externos. (MOSCOVICI, 2003, p. 29)
\end{abstract}

Na visão moscoviciana, representar alguma coisa e ter consciência de alguma coisa se assemelham em processo. A representação não se configura como uma instância

\footnotetext{
${ }^{1}$ Niels Bohr - Recebeu o prêmio Nobel em 1922 por seu trabalho sobre estrutura atômica.
}

\section{POLÊM!CA $\mid$ LABORE}

Polêmica - Revista Eletrônica da Uerj - Rua São Francisco Xavier, 524, $1^{\circ}$ andar

bloco D, sl.1001 • Tels.: +55 21 2334-4088/4087 • http://www.e-publicacoes.uerj.br/index.php/polemica/index http://www.labore.uerj.br • laboreuerj@yahoo.com.br 
intermediária, mas como um processo que engendra, de forma recíproca, percepção e conceito. Na relação com o objeto, a representação tem um status de gênese desta relação, na medida em que "a condição de seu aparecimento é uma supressão do objeto ou da entidade concreta; mas por outro lado, essa supressão não pode ser total e, a exemplo da atividade perceptiva, a percepção deve recuperar esse objeto ou essa entidade, e torná-los tangíveis" (MOSCOVICI, 2003, p. 58).

Através da Teoria das Representações Sociais, Moscovici (1978) sistematiza estas ideias. Mostra que a passagem da ciência para as das representações sociais implica uma descontinuidade, um salto de um universo de pensamento e de ação a um outro, e não uma continuidade, uma variação do mais ao menos. Constitui uma ruptura. Essa ruptura é a condição necessária para a "entrada de cada conhecimento físico, biológico, psicológico e etc., no laboratório da sociedade. Todos eles aí se encontram, dotados de um novo status epistemológico, sob a forma de representações sociais" (MOSCOVICI, 1978, p. 26). Para ele, as Representações Sociais têm relação direta com o comportamento humano criador, na medida em que elas são dotadas de função constitutiva da realidade.

Assim, "as representações individuais ou sociais fazem com que o mundo seja o que pensamos que ele é ou deve ser. Mostram-nos que, a todo instante, alguma coisa ausente se lhe adiciona e alguma coisa presente se modifica" (MOSCOVICI, 1978, p. 59). Deste modo, sempre existirá alguma coisa ao invés do nada.

\section{Referências}

BOTELLA, C.; BOTELLA, S. Irrepresentável: mais além da representação. Porto Alegre: Sociedade de Psicologia do Rio Grande do Sul/Criação Humana, 2002.

FREUD, S. (1932). Novas contribuições à psicanálise. Uma concepção do universo (XXXV). In: . Obras Completas de Sigmund Freud. Tradução: Dr. Gladstone Parente. v. 17. Rio de Janeiro: Delta, [s.d.]. p.167-192. (1900). Interpretação dos Sonhos. Tomo II. Psicologia dos processos oníricos. In: Obras Completas de Sigmund Freud. Tradução: Dr. Gladstone Parente. v. 4. Rio de Janeiro: Delta, [s.d.]. p.281-387. GARCIA-ROZA, L. A. Freud e o inconsciente. Rio de Janeiro: Zahar, 1987.

Introdução à metapsicologia Freudiana. v. 1: sobre as afasias (1891): O projeto de 1895. Rio de Janeiro: Zahar, 1991.

GONDAR, J. Os tempos de Freud. Rio de Janeiro: Revinter, 1995.

GUITTON, J.; BOGDANOV, G.; BOGDANOV, I. Deus e a ciência. Rio de Janeiro: Nova Fronteira, 1993.

\section{POLÊM!CA $\mid$ LABORE}


KOYRÉ, A. Estudos de história do pensamento científico. Rio de Janeiro: Forense Universitária, 1991.

LAPLANCHE, J. Vocabulário da Psicanálise: Laplanche e Pontalis. Sob a direção de Daniel Lagache. Tradução: Pedro Tamen. São Paulo: Martins Fontes, 2001.

MOSCOVICI, S. A representação social da psicanálise. Rio de Janeiro: Zahar, 1978.

A máquina de fazer deuses. Rio de Janeiro: Imago, 1990.

Representações sociais: investigações em psicologia social. Tradução: Pedrinho A. Guareschi. Petrópolis: Vozes, 2003.

OGDEN, T. H. Esta arte da Psicanálise: Sonhando sonhos não sonhados e gritos interrompidos. Tradução: Daniel Bueno. Porto Alegre: Artmed, 2010.

TANIS, B. Memória e temporalidade: o infantil em psicanálise. São Paulo: Casa do psicólogo, 1995.

WINNICOTT, D. W. O ambiente e os processos de maturação: estudos sobre a teoria do desenvolvimento emocional. Tradução: Irineo Constantino Schuch Ortiz. Porto Alegre: Artmed, 1983.

ZORNIG, S. A. A criança e o infantil em psicanálise. São Paulo: Escuta, 2008.

Recebido em: 19/07/2016.

Aceito em: 31/08/2016.

\section{POLÊM!CA $\mid$ LABORE}

Polêmica - Revista Eletrônica da Uerj - Rua São Francisco Xavier, 524, $1^{\circ}$ andar bloco D, sl.1001 • Tels.: +55 21 2334-4088/4087 • http://www.e-publicacoes.uerj.br/index.php/polemica/index http://www.labore.uerj.br • laboreuerj@yahoo.com.br 